\title{
Nutritional Profile and Impact of Fig Leaves Powder Supplementation on Selected Type 2 Diabetic Subjects of Calicut District
}

\author{
S. Angeline Esther Preethi ${ }^{1 *}$ and M. K. Anjupriya ${ }^{2}$ \\ 'Associate Professor and Head, Rathnavel Subramaniam College of Arts and Science (Autonomous), Sulur, \\ Coimbatore -641402, Tamil Nadu, India; preethi_samson@yahoo.co.in \\ ${ }^{2}$ PG Student, Department of Foods and Nutrition, Rathnavel Subramaniam College of Arts and Science \\ (Autonomous), Sulur, Coimbatore - 641402, Tamil Nadu, India
}

\begin{abstract}
Two hundred adult diabetic patients were selected and information pertaining to their personal, nutritional and medical history was collected in an attempt to find out their nutritional status. Biochemical parameters namely random blood sugar, post prandial blood glucose level and glycosylated haemoglobin level were estimated to find out the blood sugar level in the body. Forty mild diabetic women in the age group of 40-49 years who were under dietary management only were selected for the supplementation study. Twenty women $(\mathrm{n} 1=20)$ were considered as the experimental group for whom $10 \mathrm{~g}$ of fig leaf powder was mixed in $100 \mathrm{ml}$ of buttermilk and given for a period of one month. The remaining 20 (control group $\mathrm{n}=20$ ) were given nutrition education. The impact of the supplementation study was assessed by comparing the blood glucose level of experimental group and control group. It was observed that half of the patients were mild diabetic and the incidence of the disease was only a year ago. There was a significant decrease in the blood glucose level of the experimental group which proves the hypoglycaemic effect of fig leaves.
\end{abstract}

Keywords: Diabetes Mellitus, Fig Leaves, Blood Glucose Level

\section{Introduction}

Diabetes mellitus (DM) is a chronic metabolic disease, which is rapidly increasing due to the changes in our life style. According to (Emmanual, 2010) f, "The chronic metabolic disorder diabetes mellitus is a fast-growing global problem with huge social, health, and economic consequences". As Hamdard, 9 reported, "Diabetes mellitus is a constellation of metabolic diseases in which there are high blood sugar levels over an extended period. The metabolic disharmony associated with DM causes a number of secondary pathological changes in multiple organ systems which impose a huge burden on the individual with diabetes and also on the entire health care system of the country". According to the World Health Organization (WHO) report, India today heads the world with over 32 million diabetic patients and this number is projected to increase to 79.4 million by the year 2030 (Balachandra et al., 2016) Deng: stated "Food supplements have increasingly become attractive alternatives to prevent or treat hyperglycemia, especially for subjects with mild hyperglycemia". According to Jantan et al., "Ficuscarica L. (Moraceae), has been used traditionally to treat various ailments such as gastric problems, inflammation, and cancer. Phytochemical studies on the leaves and fruits of the plant have shown that they are rich in phenolics, organic acids, and volatile compounds. Some of the most interesting 
therapeutic effects include anticancer, hepatoprotective, hypoglycemic, hypolipidemic, and antimicrobial activities". Sethi offer powerful blood lowering effects by increasing the sensitivity of insulin to glucose. Its blood sugar lowering effect, fig leaves are strong antioxidants and antiinflammatory in nature. Fig leaves lower the oxidative stress typical in diabetes and help in wound healing via its anti inflammatory action". So the present study was undertaken to study the associated symptoms of diabetes mellitus in patients and also to assess the impact of fig leaf powder supplementation.

\section{Materials and Methods}

Two hundred adult diabetic patients in the age group of 40 to 54 years were selected from MIMS hospital Calicut for the study. An interview schedule was formulated to collect the personal details, nutritional details and medical history of the patient. The nutrition assessment comprised of anthropometric parameters, biochemical assessment and dietary assessment. The biochemical assessment included estimation of fasting blood glucose, postprandial blood sugar and glycosylated haemoglobin test for all the 200 subjects. Medical history of a patient was assessed based on the present complaints, past medical history and also the associated complications. The detail of dietary intake was done by 24 hours dietary recall. In this study 40 mild diabetic women subjects (100$125 \mathrm{mg} / \mathrm{dl}$ ) who were treated with dietary management alone were selected for the intervention feeding trial. The experimental group comprised of 20 subjects who were given $10 \mathrm{gm}$ of fig leaf powder in buttermilk for 30 days. The remaining 20 subjects were kept as the control group for whom nutrition education was given. The fresh leaves of Ficus Carica were collected from the local area of Calicut district. It was dried in microwave oven at $121{ }^{\circ} \mathrm{C}$ for 10 minutes, then allowed to cool in room temperature and ground in a miller to obtain fig leaves powder. The impact of intervention were analysed by using the random blood glucose level and the incidence of diabetes associated complications.

\section{Result and Discussion}

\subsection{Personal Details}

Among the selected subjects $102(50 \%)$ of the selected subjects were in the age group of 40-45 years. There was equal distribution of males and females in the study. Nearly ninety percent of the subjects were involved in sedentary life style.Highest number of subjects (64\%) belonged to high income group.

\subsection{Nutritional Assessment}

The BMI of the subjects (Table 1) revealed that a majority of 70 females and 32 males were in Grade I obesity. A total of 15 subjects were in underweight category and 44 were in the ideal weight category.Energy was deficient by $180 \mathrm{kcal}$ and proteins by $7.59 \mathrm{~g}$. The intake of fat was $15.08 \mathrm{~g}$ more than their RDA.

Table 1. Mean anthropometric parameters of the selected subjects $(\mathrm{N}=200)$

\begin{tabular}{|l|c|c|c|c|c|}
\hline \multirow{2}{*}{ PARAMETER } & \multirow{2}{*}{ AGE(YEARS) } & \multicolumn{2}{|c|}{ MEN } & \multicolumn{2}{c|}{ WOMEN } \\
\cline { 2 - 6 } & & STD & MEAN & STD & MEAN \\
\hline \multirow{3}{*}{ HEIGHT(CM) } & $40-44$ & 172.3 & 171.6 & 161.6 & 159.4 \\
\cline { 2 - 6 } & $45-49$ & 172.1 & 170.1 & 160.6 & 159.2 \\
\cline { 2 - 6 } & $50-54$ & 171.8 & 168.8 & 160.3 & 159.8 \\
\hline \multirow{3}{*}{ WEIGHT(KG) } & $40-44$ & 66 & 67.8 & 61.3 & 64.4 \\
\cline { 2 - 6 } & $45-49$ & 66.2 & 69.2 & 61.8 & 65.3 \\
\cline { 2 - 6 } & $50-54$ & 66.6 & 67.5 & 61 & 63.6 \\
\hline \multirow{3}{*}{ BMI } & $40-44$ & $18.5-25$ & 26.3 & 18.5 & 26.5 \\
\cline { 2 - 6 } & $45-49$ & $18.5-25$ & 27.4 & $18.5-25$ & 27.8 \\
\cline { 2 - 6 } & $50-54$ & $18.5-25$ & 27.6 & $18.5-25$ & 28.2 \\
\hline
\end{tabular}

${ }^{*}$ STD-95 ${ }^{\text {TH }}$ PERCENTILE VALUE GIVEN BY ICMR, 2010. 
Table 2. Biochemical parameters of the selected subjects

\begin{tabular}{|l|l|c|c|}
\hline PARAMETER & CATEGORY & Number of subjects & Percentage \\
\hline \multirow{5}{*}{ Fasting Blood Glucose Level } & Mild(Less than $100 \mathrm{mg} / \mathrm{dl})$ & 101 & 50.5 \\
\cline { 2 - 4 } & Moderate $(100-125 \mathrm{mg} / \mathrm{dl})$ & 27 & 13.5 \\
\cline { 2 - 4 } & Severe(>126mg/dl) & 62 & 31 \\
\hline \multirow{5}{*}{ Glycosylated Hb Level } & Non Diabetes(6\%) & 5 & 2.5 \\
\cline { 2 - 4 } & Pre Diabetes(6-6.4\%) & 94 & 57 \\
\cline { 2 - 4 } & Type 2 Diabetes (Above 6.5\%) & 101 & 50.5 \\
\hline Post Prandial Blood Glucose Level & Mild(70-140mg/dl) & 100 & 50 \\
\cline { 2 - 4 } & Moderate(140-200mg/dl) & 54 & 27 \\
\cline { 2 - 4 } & Severe(>200mg/dl) & 46 & 23 \\
\hline
\end{tabular}

Table 3. Impact of supplementation

\begin{tabular}{|l|c|c|c|c|}
\hline \multirow{2}{*}{ GROUP } & \multicolumn{2}{|c|}{ Mean fasting Blood Glucose Level (mg/dl) } & t- value & \multirow{2}{*}{ Level of Significance } \\
\cline { 2 - 5 } & BEFORE SUPPLEMENTATION & AFTER SUPPLEMENTATION & & \\
\hline $\begin{array}{l}\text { Experimental } \\
\text { Group }\end{array}$ & $118 \pm 4.51$ & $102 \pm 5.21$ & 7.38 & $*$ \\
\hline Control Group & $102.4 \pm 5.61$ & $101.6 \pm 5.8$ & 1.52 & NS \\
\hline
\end{tabular}

${ }^{*}$ Significant at 5\% level, NS-Non significant.

It is evident from Table 2 that majority (50.5\%) were mildly diabetic and were categorized under type 2 diabetes.

\subsection{Medical History}

It was noted that 101 patients were diagnosed with diabetes within the past one year of the study and 38 patients had diagnosed 5 years back. Among the 200 subjects studied it was found that 49 subjects stated that both their parents had diabetics which indicates the heredity link to diabetes mellitus.

There was a gradual decrease of the symptoms like polyuria, polyphagia, polydipsia, delayed wound healing and nocturia in the experimental group after figleaf powder supplementation. There was a significant reduction in the fasting blood glucose level (Table 3 ) of the subjects in the experimental group after the supplementation of fig leaf powder.

\section{Conclusion}

From the result of the study it can be concluded that obesity and sedentary life style was a major factor noted in the subjects. The diabetic subjects were experiencing medical problems which if not treated may lead to other organ damages. The supplementation of fig leaf powder had a significant impact in the fasting blood glucose level. Identification and use of hypoglycaemic ingredients such as fig leaves can be effective tool for treating and managing diabetes mellitus.

\section{References}

1. Emmanual K. Diagnosis and classification of diabetes mellitus. Indian Journal of Standards of Medical Care in Diabetes. $2010 ; 4(2): 143-56$.

2. Hamdard. Complications of Diabetes. Journal of Diabetic Control. 2015; 10(4):89-99.

3. Balachandra T, Tamang I, Alagu S, Mellina. Prevalence of Diabetes mellitus. Journal of Diabetes Control. 2016; 19(3):321-453.

4. Deng J. Article on hypoglycemic foods. The Journal of Plant Nutrition. 2011; 3(10):543-674.

5. Jantan P, Raquel C, Subash K, Nutritional diagnosis of fig tree leaves. The Journal of Annals of Family Medicine. 2010; 1(3):543-83.

6. Sethi. Effect of organic fertilization on fig leaves. Journal of Applied Pharmaceutical Science. 2010; 12(4):212-321. 